\title{
Analysis of the Influence of Water-cement Ratio on Concrete Strength
}

\author{
Wei LI ${ }^{1}$ \\ ${ }^{1}$ Yantai International Airport Group Co., Ltd, Yantai, Shandong, China
}

\begin{abstract}
In this paper, the main strength of the relationship between water-cement ratio and concrete, and it uses the contrast test of different water cement ratio, finally, it gets the regular change between water cement ratio and concrete strength. The test results show that: cement. when the ratio of large stone: small stone: water: admixture is 340: 618: 1009: 433: 139: 6.8, the water-cement ratio of concrete is within the range of $0.371-0.479$. The concrete strength of the sample decreases with the increase of the water-cement ratio. Finally, the relationship between the concrete strength and the water-cement ratio is obtained by fitting.
\end{abstract}

\section{Introduction}

With the accelerated development of the country, the construction industry has shown great vitality. The quality of concrete is the guarantee of construction, the foundation of the construction industry, and the cornerstone of rapid development. In order to ensure the quality of concrete, we need to mix cementing materials, aggregates or other admixtures, in which part of the water used to mix the concrete is used for the cement hydration reaction and the other part is used to improve the workability of the concrete. When the amount of cement is the same, the ratio of water cement is too large or too small, which is not conducive to the improvement of cement concrete strength. Therefore, more attention should be paid to the water-cement ratio of concrete. ${ }^{[1]}$

According to previous studies by scholars, the main factors affecting the flexural strength of concrete mainly include the water-cement ratio and the related properties of aggregate, among which the water-cement ratio is still one of the most important factors affecting the flexural strength of cement concrete ${ }^{[2]}$. Wang $\mathrm{N}^{[3]}$ et al. took the water-cement ratio as the control variable to make test samples and studied the variation rule of the compressive strength and permeability of foamed concrete. Liu D. D. ${ }^{[4]}$ and Li Z. ${ }^{[5]}$ studied the influence of water-cement ratio on the performance of pervious concrete. Xie W. W. ${ }^{[6]}$, a scholar, tested the compressive strength of concrete with different water-cement ratio, lime content and phosphorus slag content, and obtained the variation rule of concrete's compressive strength with the three factors. Li S ${ }^{[7]}$ et al. mainly studied the nonlinear characteristics of concrete strength and established a multivariate nonlinear model between parameters such as fly ash content and strength.

Therefore, this paper carried out control tests under different water-cement ratios to study the influence of different water-cement ratios on the strength of concrete.
The regression relationship between water cement ratio and concrete strength is established. It provides reference for mix design of high performance concrete in the future.

\section{Experimental principle and thought}

\subsection{Test principle}

According to relevant codes and construction experience, the concrete design takes the compressive strength as the design index, so the research on the water-cement ratio and the compressive strength of concrete is more in-depth. At present, the more common method is to use Paul's formula to estimate the water-cement ratio of concrete:

$$
R_{28}=A R_{\mathrm{c}}\left(\frac{W}{C}-B\right)
$$

There is: $R_{28}$ The compressive strength of concrete at 28 days;

$\mathrm{A}$ and $\mathrm{B}$ are the coefficients;

$R_{\mathrm{c}}$ - The compressive strength of cement at 28 days;

$\frac{W}{C} \longrightarrow$ Water-cement ratio.

\subsection{Test idea}

Based on the mix ratio of cement pavement concrete, this study further studies how the water-cement ratio affects the strength of concrete. Specific mix ratio is: cement: sand: big stone: small stone: water: admixture $=340: 618$ : 1009: 433: 139: 6.8. The test configuration cement content is $\mathrm{A}-50, \mathrm{~A}-45 \ldots \mathrm{A}, \mathrm{A}+5 . .$. For 18 kinds of cement 
concrete of $\mathrm{A}+35$, three cylindrical specimens and three trabecular specimens were prepared for each water-cement ratio, A total of 54 cylindrical specimens and 54 trabecular specimens were tested for their flexural tensile strength respectively.

\section{Experiment}

\subsection{The raw materials}

The cement used in this test is "Qixia" brand P.042.5 grade bulk cement produced by Qixia Zhonglian Cement Co., Ltd., Yantai. which has been tested by relevant units and all indicators meet the standard requirements.

\section{(2) Aggregate}

The fine aggregate used in this test is river sand. and the technical indexes are shown in Table 1:

\section{(1) Cement}

Tab.1 results of fine aggregate screening

\begin{tabular}{lccc}
\hline Number & The test items & The measured values & Standard values \\
\hline 1 & $\mathrm{Cl}^{-}$ & $0.014 \%$ & $\leq 0.02$ \\
2 & $\mathrm{SO}_{3}$ & $0.2 \%$ & $\leq 0.5$ \\
3 & Robustness & $4.9 \%$ & $\leq 8$ \\
4 & Alkali active reaction & Inactive & $\leq 1$ \\
5 & Mica and light matter content & $0.5 \%$ & Shactive \\
6 & Organic content & Shallow
\end{tabular}

Coarse aggregate was mixed with $4.75 \sim 16 \mathrm{~mm}$ and

16 .31.5 mm gravel produced in Qixia quarry.

Tab. 2 Screening results of coarse aggregate

\begin{tabular}{|c|c|c|c|}
\hline Number & The test items & The measured values & Standard values \\
\hline 1 & Sulfides and sulfates a & $0.7 \%$ & $\leq 1$ \\
\hline 2 & Chloride content & $0.013 \%$ & $\leq 0.02$ \\
\hline 3 & Red and white skin content of gravel b & $5.2 \%$ & $\leq 10$ \\
\hline 4 & The compressive strength of rock & $126 \mathrm{MPa}$ & $\geq 100$ \\
\hline 5 & Los Angeles attrition loss & $26 \%$ & $\leq 30$ \\
\hline 6 & Organic content & $\begin{array}{c}\text { The color is lighter than standard } \\
\text { solution }\end{array}$ & $\begin{array}{l}\text { The color is lighter than standard } \\
\text { solution }\end{array}$ \\
\hline 7 & Activity of alkali & Inactive & Inactive \\
\hline 8 & Bibulous rate & $0.6 \%$ & $\leq 2$ \\
\hline 9 & Robustness & 1.9 & $\leq 3$ \\
\hline
\end{tabular}

\section{(3) Admixture}

According to the site conditions of this construction, the admixture selected in this test is AJF air entrain efficient water reducing agent, which meets the requirements of the experiment.

\section{(4) Water}

The water must pass the relevant test indicators required by the specification.

\subsection{The process of experiment}

According to the test scheme, there are 18 groups of tests, with 3 cylinder samples and 3 trabecular samples in each group, a total of 54 cylinder samples and 54 trabecular samples. The splitting tensile strength and bending tensile strength of the specimen were tested after curing. 


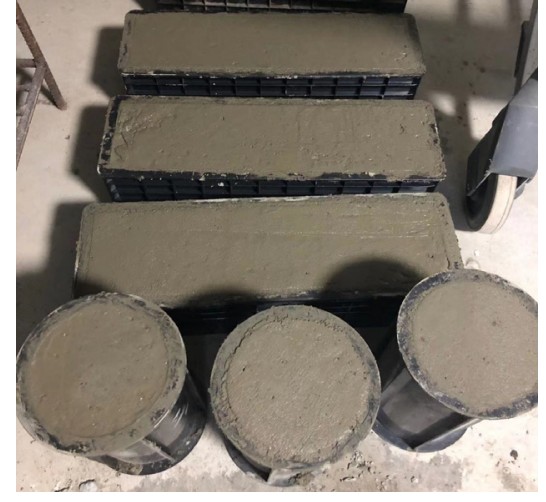

Fig. 1 Experimental process

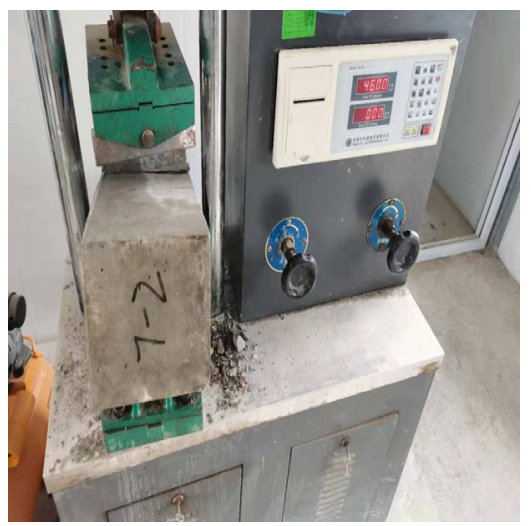

Fig. 2 Strength test
Tab.3 bending tensile strength of samples with different water-cement ratios

\begin{tabular}{ccc} 
Number & Cleavage strength $(\mathrm{MPa})$ & Water-cement ratio \\
\hline 1 & 6.27 & 0.479 \\
2 & 6.51 & 0.471 \\
3 & 6.40 & 0.463 \\
4 & 5.86 & 0.456 \\
5 & 6.08 & 0.448 \\
6 & 6.51 & 0.441 \\
7 & 6.54 & 0.434 \\
8 & 6.23 & 0.428 \\
9 & 6.29 & 0.421 \\
10 & 6.83 & 0.415 \\
11 & 6.44 & 0.409 \\
12 & 7.25 & 0.403 \\
13 & 6.70 & 0.397 \\
14 & 7.45 & 0.392 \\
15 & 6.61 & 0.386 \\
16 & 6.98 & 0.381 \\
17 & 7.13 & 0.376 \\
18 & 7.54 & 0.371 \\
\hline
\end{tabular}

\subsection{Analysis}

After the numerical statistical analysis of the obtained data, the bending tensile strength measured in the test was plotted into a scatter plot with the water-cement ratio as the abscissor, and the quadratic polynomial was selected for fitting to obtain the relationship as shown in Fig.3.

\section{Test results and analysis}

\subsection{Results}

Through the above tests, the experimental results obtained are shown in Table 3 below.

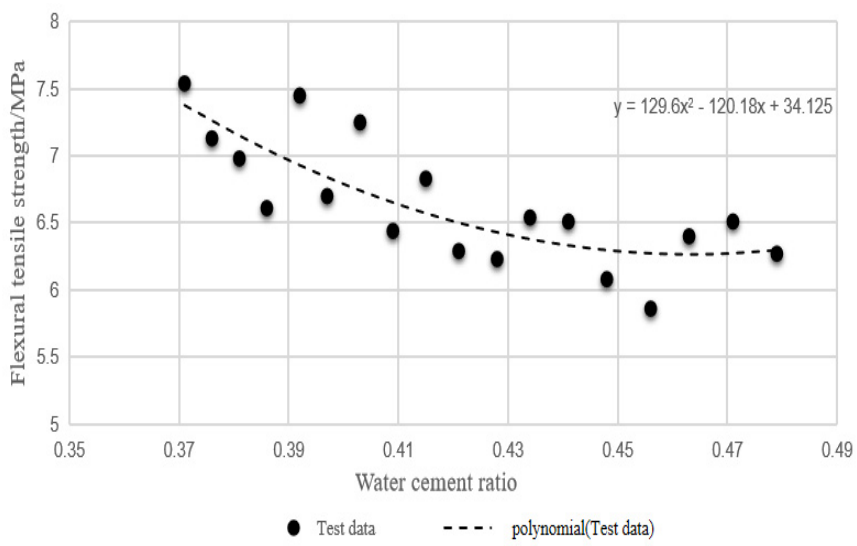

Fig.3 Relationship between bending tensile strength and water-cement ratio

It can be seen from the relation diagram of water-cement ratio and bending tensile strength that when the water-cement ratio of concrete is $0.371 \sim 0.479$, the quadratic polynomial is used to perform fitting, and the following formula is obtained:

$$
\sigma_{b}=129.6\left(\frac{W}{C}\right)^{2}-120.18\left(\frac{W}{C}\right)+34.125
$$

There is: $\sigma_{\mathrm{b}}$-Flexural strength, $M P a$;

$\frac{W}{C}-$ Water-cement ratio.

When the water cement is larger, the concrete compactness decreases. Reduced water cement ratio, cement concrete flexural strength will reduce gradually, based on the analysis of the stress of the concrete trabecular bend test, presumably because the trabecular 
bending test of concrete at the bottom of the tensile stress in the largest part of trabecular line position, maximum stress area is linear distribution, the maximum stress zone is the probability of cement mortar, aggregate interface vulnerabilities are relatively small, As the water-cement ratio increases, due to the reduction of free water after hydration, the cement slurry itself tends to be compacted, which increases the bearing capacity in the maximum stress area of the trabecular specimen and ultimately increases the bending and tensile strength of the measured specimen.

\section{Conclusion}

In this experiment, the influence of water-cement ratio on concrete performance is studied, and the change of concrete performance is analyzed by changing the water-cement ratio of concrete, and the change relationship between water-cement ratio and concrete strength is established. The main conclusions are as follows:

(1) When the water-cement ratio of concrete is in the range of $0.371 \sim 0.479$, the concrete strength of the sample decreases with the increase of water-cement ratio.

(2) The relationship between concrete strength and water-cement ratio obtained by fitting is as follows:

$$
\sigma_{b}=129.6\left(\frac{W}{C}\right)^{2}-120.18\left(\frac{W}{C}\right)+34.125
$$

In the future research, we will increase the multi-factor study of aggregate and sand rate, etc., to describe their influence rules on concrete strength in a more detailed manner.

\section{Reference}

1. Yang, Z.Z. (2020) Strength characteristics of hardened cement paste at low water binder ratio[D]. Hefei university of Technology.

2. Yao, Y. (2018) Study on reparation of reactive powder concrete and the influence factors on its strength[D]. Shenyang Jianzhu University.

3. WANG, N., LIU C.L., WU, J. (2020) Influence of water-grey ratio on pressure strength and permeability of borehole-support[J]. Coal Science \& Technology, 41(06): 18-21.

4. LIU, D.D., SUI, W.X. (2020) Analysis of the influence of water cement ratio on the performance of pervious concrete [J]. Concrete, (11):141-143.

5. Li, Z. (2019) Study on the effect of different water-cement ratio on the performance of permeable concrete $[\mathrm{J}]$. Hunan Communication Science and Technology, 45(01):56-58+91.

6. Xie, W.W. (2020) Mix Proportion Design and Strength Prediction Method of Building Concrete [J]. Municipal Engineering Technology, 38(03):290-292.

7. Li, S., Du, Y.J. (2016) Concrete strength prediction model based on multivariate nonlinear analysis [J]. Concrete, (03):44-46+5 